\title{
The nutritional control of root development
}

\author{
Brian Forde ${ }^{1,3} \&$ Helena Lorenzo ${ }^{2}$ \\ ${ }^{1}$ Department of Biological Sciences, Lancaster University, LA1 4YQ Lancaster, UK ${ }^{2}$ Biochemistry and Physiology \\ Department IACR-Rothamsted, Harpenden, $U K^{3}$ Corresponding author*
}

Key words: Nitrate, nutrients, plasticity, root development, signalling, trophomorphogenesis

\begin{abstract}
Root development is remarkably sensitive to variations in the supply and distribution of inorganic nutrients in the soil. Here we review examples of the ways in which nutrients such as N, P, K and Fe can affect developmental processes such as root branching, root hair production, root diameter, root growth angle, nodulation and proteoid root formation. The nutrient supply can affect root development either directly, as a result of changes in the external concentration of the nutrient, or indirectly through changes in the internal nutrient status of the plant. The direct pathway results in developmental responses that are localized to the part of the root exposed to the nutrient supply; the indirect pathway produces systemic responses and seems to depend on long-distance signals arising in the shoot. We propose the term 'trophomorphogenesis' to describe the changes in plant morphology that arise from variations in the availability or distribution of nutrients in the environment. We discuss what is currently known about the mechanisms of external and internal nutrient sensing, the possible nature of the long-distance signals and the role of hormones in the trophomorphogenic response.
\end{abstract}

Abbreviations: ABA, abscisic acid; NR, nitrate reductase; $\mathrm{P}_{\mathrm{i}}$, inorganic phosphate

\section{Introduction}

The difficulty lies not in the new ideas, but in escaping the old ones.

\section{John Maynard Keynes.}

A characteristic feature of plant development is that it does not follow a rigidly predefined plan but instead is continuously susceptible to modification by interactions with the environment. A major function of this plasticity is to enable plants to overcome some of the constraints of their sessile lifestyle and to explore their surroundings for essential resources such as light, water and nutrients. Above ground, variations in light intensity and quality elicit photomorphogenic responses such as changes in internode and petiole length and in leaf area and thickness (Grime et al., 1986). In ecological terms, these responses provide a means by which plants can forage for light in com-

\footnotetext{
* Fax: +44(0)1524-843854. E-mail:b.g.forde@lancaster.ac.uk
}

petition with their neighbours. Below ground, there is equally strong competition for edaphic resources (water and nutrients). As with light, the supply of these is variable in both space and time and can frequently limit growth. It is therefore not surprising that root development, like shoot development, is highly plastic and that roots too manifest a foraging response when presented with localized supplies of nutrients (Robinson, 1994).

While rapid progress is being made in elucidating the phytochrome-mediated signal transduction pathways that convert light signals into morphological responses (Ballaré, 1999; von Arnim, 1999), much less attention has been paid to how nutritional signals are perceived and transduced in plants. Here we will first review the variety of ways in which nutrient supply affects root development and then go on to discuss the relative contributions of localized and systemic regulatory mechanisms. The remainder of the review will examine how far we have got in understanding the molecular basis for nutritional control of root development. 


\section{Developmental processes in the root influenced by nutrient supply}

It is appropriate at this point to insert some notes of caution. In considering the examples of nutritional modification of root development described here, it should be appreciated that in many cases data are available only for a small number of plant species. One thing that is clear about developmental plasticity is that different species (and even different genotypes within a species) can and often do respond differently to the same environmental stimulus. These differences in response are usually quantitative, but there is at least one example where the same nutritional stimulus elicits the opposite response in two genotypes of the same species (Bonser et al., 1996). Thus although many of the responses discussed here have been selected because they are well-documented and have been observed in more than one species, it may not be safe to extrapolate to untested species or genotypes. It is also undoubtedly the case that the responsiveness of a plant to a particular nutritional stimulus is likely to be influenced by interactions with other environmental variables, so that the experimental conditions could well have a strong influence on the observed responses.

Another aspect of plant biology which could sometimes complicate the assessment of nutritional effects on plant development is the phenomenon of 'ontogenetic drift', whereby many phenotypic traits change dramatically during the course of plant growth and development (Coleman et al., 1994; Evans, 1972). For this reason, if a nutrient treatment affects the rate of growth and development (and is being applied for long enough to do so significantly) then it may not be meaningful to compare the morphology of plants of the same chronological age. In such cases it may be necessary to use plant size or developmental stage as the basis for comparisons (Coleman et al., 1994; Evans, 1972). This can be particularly relevant in the case of the shoot:root ratio, which in some herbaceous plants increases markedly over the first few weeks of growth (Bazzaz et al., 1989). While ontogenetic drift is unlikely to be a major factor in any of the other morphogenetic effects discussed below, it will always be important to keep the phenomenon in mind when assessing any apparent examples of phenotypic plasticity in plants.

\section{Root growth and branching}

One of the most commonly observed effects of nutrient deficiency on plant development is a decrease in the shoot:root ratio, particularly in fast-growing species adapted to sites of high fertility (Chapin, 1980). Deficiencies in $\mathrm{N}, \mathrm{P}$ or $\mathrm{S}$ all result in a shift in dry matter allocation in favour of root growth (Ericsson, 1995). However, simple measurement of the relative biomass of the shoot and root fails to reveal the many subtleties of the roots' response to changes in nutrient supply. For example, while K deficiency does not affect the shoot:root ratio in barley (Hordeum vulgare) (Drew, 1975) it does cause marked changes in root architecture by inhibiting lateral root growth without affecting seminal root growth or the numbers of primary lateral roots (Hackett, 1967).

Nearly 140 years ago it was reported that plants growing on concentrated nutrient solutions developed a short, compact and densely branched root system, while on dilute solutions or water the roots were long, thin and more sparsely branched (Nobbe, 1862). This general response to variations in the nutrient supply has since been reported many times in a wide range of species (reviewed by Wiersum, 1958). In his studies, Wiersum noted that nutrient deficiency (particularly $\mathrm{NO}_{3}{ }^{-}$deficiency) produced faster-growing taproots and diminished root branching in several dicot species. In barley, deficiencies in $\mathrm{N}, \mathrm{P}$ or $\mathrm{K}$ all led to a marked decrease in the lengths of both first- and second-order lateral roots, while seminal root length was unaffected (Drew, 1975). A similar response to $\mathrm{P}$ deficiency was noted in maize (Zea mays) (Mollier and Pellerin, 1999). Note that it seems to be a general rule in plants that primary root growth is much less sensitive to nutritional effects than is the growth of secondary or higher-order roots

The positive effect of nutrients on root branching becomes most apparent when the nutrient supply is localized in the soil. On encountering a soil patch that is rich in nutrients (particularly $\mathrm{N}$ or $\mathrm{P}$ ), the roots of many plant species respond with an increased rate of root growth and branching that is localized to the nutrient-rich patch (Robinson, 1994). This response enables the plant to optimize its allocation of resources by concentrating its root growth within the region of the soil that will yield the most benefit in terms of nutrient capture. It has been shown to be of particular ecological importance in situations where neighbouring plants are competing for limited resources (Hodge et al., 1999; Robinson et al., 1999). 
The first detailed experiments describing the plant's responses to localized supplies of individual macronutrients were performed on barley by Drew and his colleagues (Drew, 1975; Drew and Saker, 1975, 1978; Drew et al., 1973). These demonstrated the spectacular way in which $\mathrm{NO}_{3}^{-}, \mathrm{NH}_{4}{ }^{+}$or $\mathrm{P}_{i}$ (inorganic phosphate), when applied to one segment of a seminal root, stimulated lateral root proliferation specifically within that segment. The increased root proliferation was the result of increased numbers of both primary and secondary lateral roots and a significant stimulation of the elongation rate of the lateral roots in the zone of treatment. Of the nutrients tested, only $\mathrm{K}$ failed to elicit a response, and studies on other species have confirmed the absence of localized proliferation in K-rich patches (Robinson, 1994). Why there should be this difference between $\mathrm{K}$ and other macronutrients is unclear.

Recent studies with Arabidopsis showed that a localized supply of $\mathrm{NO}_{3}{ }^{-}$stimulated lateral root elongation by 2 - to 3 -fold in the $\mathrm{NO}_{3}{ }^{-}$-rich zone and that even $0.1 \mathrm{~mm} \mathrm{NO}_{3}{ }^{-}$(when the rest of the root received $0.01 \mathrm{~mm}$ ) was sufficient to elicit the maximal response (Zhang et al., 1999). Unlike barley, but similar to maize (Sattelmacher and Thoms, 1995), the localized $\mathrm{NO}_{3}{ }^{-}$supply had no significant effect on lateral root initiation.

Intriguingly, a recent report suggests that it is not only macronutrients that are able to trigger a localized branching response. When one-half of a split-root system of the Zn hyperaccumulator species Thlaspi caerulescens was exposed to soil enriched for $\mathrm{Zn}$ (at 250-1000 mg kg-1 soil), that portion of the root system showed increased biomass and length (Whiting et al., 2000). These experiments showed that hyperaccumulator species have the ability to forage for metals at concentrations that are inhibitory to root growth in non-accumulator species from the same genus. This unexpected observation raises the question whether the ability to perceive and respond to heavy metals (and perhaps other micronutrients) is widespread amongst plants. In non-accumulator or metal intolerant species the response would only be detectable at a much lower range of heavy metal concentrations because of the inhibitory effects of metal toxicity on root growth.

Although lateral roots may respond to localized supplies of a nutrient in a localized fashion, this response is not necessarily completely autonomous because the intensity of the response can also be affected by the nutrient supply to the rest of the root system. Thus, for example, an external supply of $1 \mathrm{mM} \mathrm{NO}_{3}{ }^{-}$stimulated lateral root growth more strongly in barley when the remainder of the root system was in low $\mathrm{NO}_{3}{ }^{-}$than if it too was in high $\mathrm{NO}_{3}{ }^{-}$ (Drew et al., 1973). Similarly, roots of P-stressed bean plants presented with a P-enriched soil patch branched more intensively within the patch than did roots of unstressed plants (Snapp et al., 1995).

\section{Root diameter}

Fine roots allow the root system to explore the soil volume effectively while minimizing the investment needed to construct and maintain the root system. Thicker roots are more costly to produce, but have greater transport capacity and are less vulnerable to desiccation, physical damage, pathogens and grazing by soil-borne microarthropods and so are generally longer-lived (Fitter, 1987). Many plant species accommodate this trade-off by exhibiting plasticity in root diameter according to the environmental conditions. The fineness of a root is often expressed as specific root length (length per unit weight of root) and roots with high specific root lengths (i.e., fine roots) are often found in plants grown under nutrient deficient conditions (Fitter, 1985).

Changes in the overall fineness of a root system as a result of changes in nutrient supply can sometimes be attributed to changes in the relative proportions of different orders of root. Thus if increased branching results from an increase in the nutrient supply, the result will be an increase in the average specific root length of the root system (Bilbrough and Caldwell, 1995; Fitter, 1976; Robinson and Rorison, 1983). However, in some cases the nutrient supply can also have a direct effect on the specific root length of individual roots. For example, first order lateral roots of wheat (Triticum aestivum) growing in a $\mathrm{NO}_{3}{ }^{-}$rich patch were significantly thicker than similar roots growing in the absence of $\mathrm{NO}_{3}{ }^{-}$(Hackett, 1972). Similarly in barley, a high concentration of $\mathrm{NO}_{3}{ }^{-}$was associated with a doubling in the diameter of both firstand second-order laterals, but there was no effect on the diameter of the seminal axis (Drew et al., 1973).

Root diameter generally shows less plasticity than stem diameter, and in many species specific root length does not change significantly as a function of nutrient availability (Hutchings and de Kroon, 1994). In a comparison of a fast-growing species (Dactylis glomerata) and a slow-growing species (Brachypodium pinnatum) that co-occur in many nutrient-poor 
calcareous grasslands, it was found that only the former developed thicker roots when grown under conditions of high $\mathrm{N}$ or P (Ryser et al., 1997).

Few studies have examined the cytological basis of the plasticity in specific root length. However, Drew et al. (1978) observed that the increased diameter of lateral roots in their localized $\mathrm{NO}_{3}{ }^{-}$treatment was due to a 2 -fold increase in the diameter of the stele and in the numbers of cells in both the stele and cortex.

\section{Root angle}

An important factor in determining the distribution of the root system in the soil is the angle of growth of the roots. There are intrinsic differences between the gravitropic response of different root types within a single root system: for example secondary roots tend grow out from their parent root at an angle, allowing them to escape the nutrient depletion zone and explore the soil volume more effectively. In addition, recent studies have found that some roots display a marked plasticity in their response to gravity. This was revealed by studies in which several legume species were supplied with a range of phosphate concentrations (Bonser et al., 1996; Liao et al., this vol). Under conditions of low $\mathrm{P}$ availability the growth angle of the basal roots (the roots that emerge laterally from the base of the hypocotyl) was reduced (i.e., they became more horizontal) compared to roots adequately supplied with P. This nutritional response was observed in bean (Phaseolus vulgaris), soybean (Glycine max) and pea (Pisum sativum). Other mineral deficiencies ( $\mathrm{N}, \mathrm{K}, \mathrm{S}, \mathrm{Ca}$ or $\mathrm{Mg}$ ) had no effect on root angle.

A survey of 16 different bean genotypes revealed considerable variation in their responsiveness to $\mathrm{P}$ stress: six showed a reduced growth angle, nine failed to respond and one responded with an increased growth angle (Bonser et al., 1996). Since P availability is normally highest near the soil surface, the production of a shallower root system under P stress is likely to be an important contributor to the efficiency of $\mathrm{P}$ acquisition (Ge et al., 2000). In agreement with this, a bean genotype with high efficiency of $\mathrm{P}$ capture under field conditions had basal roots that were much more responsive to $\mathrm{P}$ stress than did a $\mathrm{P}$-inefficient genotype (Liao and Yan, 2000).

\section{Root hair length and density}

Root hairs are tubular outgrowths on the root surface that play an important role in increasing the root's ability to capture nutrients. Not only do root hairs increase the absorptive capacity of the root by greatly increasing its surface area, they also serve to expand the nutrient depletion zone around the root. The latter is particularly important for access to relatively immobile nutrients (such as P) and can make a significant contribution to the efficiency of nutrient uptake (Gahoonia and Nielsen, 1997). Root hairs have uptake systems for most if not all macro- and micronutrients (including $\mathrm{Pi}, \mathrm{K}^{+}, \mathrm{NH}_{4}{ }^{+}, \mathrm{NO}_{3}{ }^{-}, \mathrm{Cl}^{-}$and $\mathrm{Zn}^{2+}$ ) (Gilroy and Jones, 2000).

Both the density of root hairs on the root surface and their length are known to be highly sensitive to a range of environmental factors, including the supply of certain nutrients (Gilroy and Jones, 2000). Root hair production responds particularly strongly to $\mathrm{P}$ deficiency: when rape, spinach and tomato plants were grown at $\mathrm{P}_{i}$ concentrations $>100 \mu \mathrm{M}$, root hairs were infrequent and short, whereas at low $\mathrm{P}_{i}(<10 \mu \mathrm{M})$ they were long and abundant (Foehse and Jungk, 1983). Similar effects have been reported in Arabidopsis seedlings grown in culture on high and low $\mathrm{P}_{i}$ (Bates and Lynch, 1996).

In many plant species, Fe deficiency also has a marked stimulatory effect on root hair production (Schmidt, 1999). This response is seen in dicots and in non-grass monocot species as part of a series of physiological and developmental adaptations that help to mobilise Fe in the soil (known as strategy I). Roots of the Poaceae (grasses) use a different strategy involving the secretion of phytosiderophores and subsequent uptake of the Fe(III)-phytosiderophore complex (strategy II) (Schmidt, 1999). Fe deficiency substantially increased both the length and number of root hairs in Arabidopsis, the response being seen within $24 \mathrm{~h}$ of transferring the seedlings to $-\mathrm{Fe}$ medium (Moog et al., 1995).

Perhaps surprisingly, it is not only low mobility nutrients that affect root hair development. There are many reports that root hair development is also negatively affected by the $\mathrm{NO}_{3}{ }^{-}$supply (Boot and Mensink, 1990; Foehse and Jungk, 1983; Kohls and Baker, 1989; Robinson and Rorison, 1987; Thornton, 1936). In spinach (Spinacea oleracea), root hair length was 7-fold higher at $0.01 \mathrm{mM} \mathrm{NO}_{3}^{-}$compared to $1 \mathrm{mM}$ (Foehse and Jungk, 1983). Foehse and Jungk did not report the effect of $\mathrm{NO}_{3}{ }^{-}$on root hair density, but other studies have shown negative effects on root hair numbers in oil-seed rape (Bhat et al., 1979), alfalfa (Medicago sativa) (Thornton, 1936) and Casuarina cunninghamiana (Kohls and Baker, 1989). 
There seems to be much greater species-to-species variability in root hair responsiveness to $\mathrm{NO}_{3}{ }^{-}$than to P, with some species such as tomato (Foehse and Jungk, 1983) and some grasses (Robinson and Rorison, 1987) failing to show any response to $\mathrm{NO}_{3}{ }^{-}$ under the conditions tested.

Root hairs develop from a subset of root epidermal cells termed trichoblasts. The first step in root hair development is the specification of cell fate, when an epidermal cell becomes a trichoblast and destined to produce a root hair. A number of Arabidopsis genes (e.g., TTG and GL2) have been identified as important regulators of this first step (Gilroy and Jones, 2000). Subsequent developmental stages include root hair initiation (when a bulge begins to form in the trichoblast cell wall), tip elongation and finally root hair maturation. The observations that root hair length and root hair density can be affected independently by nutrient stress are consistent with genetic evidence that initiation and growth of root hairs are under separate genetic control (Gilroy and Jones, 2000; Schiefelbein et al., 1993).

Relatively little work has been done to establish which of the first two stages of root hair development (cell fate determination or root hair initiation) is sensitive to the nutrient supply to account for the observed effects on root hair density. In the case of $\mathrm{Fe}$ there is evidence that it may be trichoblast specification which is modulated. Under conditions of nutrient sufficiency, trichoblasts develop exclusively over the anticlinal walls between underlying adjacent cortical cells (Gilroy and Jones, 2000). In Fe-deficient plants, root hairs form ectopically (i.e., over periclinal cortical cell walls) (Schmidt et al., 2000), indicating that cells which would otherwise be atrichoblasts are being triggered to develop as trichoblasts. This contrasts with the effect of water stress in Arabidopsis, where a drought-induced absence of root hairs was reported to result from a block in the second step (initiation) and not in trichoblast specification (Couot-Gastelier and Vartanian, 1995).

Root hair length is determined both by the rate and by the duration of tip growth. In P-deficient Arabidopsis plants, both components of growth contributed to the increased length: the maximum rate elongation under low $\mathrm{P}$ was $67 \%$ higher than under high $\mathrm{P}$ and the duration of growth was increased from 5.5 to 8.25 h (Bates and Lynch, 1996). Thus at least three separate stages of root hair development in Arabidopsis are susceptible to regulation by the $\mathrm{P}$ supply. It will be of great interest to discover, by means of genetic approaches, whether there is one common regulatory mechanism for all three stages or whether separate pathways operate.

\section{Nodulation}

The development of $\mathrm{N}$-fixing nodules on legume roots is a highly regulated process. The number of nodules on a root system is controlled by a mechanism called 'autoregulation', in which previously formed or forming nodules suppress the development of further nodules (Schultze and Kondorosi, 1998). Split-root experiments have established that autoregulation acts systemically and that the autoregulatory signal originates in the shoot (Kosslak and Bohlool, 1984). However in addition to autoregulation, or perhaps superimposed upon it, is a strongly suppressive effect of combined $\mathrm{N}$ (especially $\mathrm{NO}_{3}{ }^{-}$) which legumes will utilise as a $\mathrm{N}$ source in preference to forming the N-fixing symbiosis (Carroll and Mathews, 1990). Nitrate inhibition of nodulation has been one of the clearest and most intensively studied examples of the nutritional control of plant development. Unlike other factors that inhibit nodulation (such as $\mathrm{pH}$, temperature or toxicity), $\mathrm{NO}_{3}{ }^{-}$does so in a very specific way without interfering with plant growth (Carroll and Mathews, 1990). However, the sensitivity of nodulation to $\mathrm{NO}_{3}{ }^{-}$is strongly dependent on the plant species and genotype (Carroll and Mathews, 1990).

Nitrate is reported to block or delay the nodulation process at a number of different stages, including both rhizobial infection (by inhibiting root hair curling and infection thread formation) and nodule development, as well as inhibiting nitrogenase activity in established nodules and triggering early nodule senescence (Carroll and Mathews, 1990). Studies on soybean have shown that if the $\mathrm{NO}_{3}{ }^{-}$treatment is delayed until $18 \mathrm{~h}$ after rhizobial inoculation its inhibitory effect is greatly diminished (Malik et al., 1987), indicating that in this species the earliest stages of nodulation are the most sensitive. In experiments with vetch (Vicia sativa) it was shown that to be effective at suppressing root hair deformation an $\mathrm{NH}_{4} \mathrm{NO}_{3}$ treatment had to begin at least $24 \mathrm{~h}$ before the addition of the rhizobial Nod factor (which is able to initiate the process of root hair curling) (Heidstra et al., 1994). The finding that the root hairs had to develop in the presence of $\mathrm{NH}_{4} \mathrm{NO}_{3}$ for its effect to be seen, suggested that the $\mathrm{NH}_{4} \mathrm{NO}_{3}$ treatment might be interfering with perception or transduction of the Nod factor signal or that that the $\mathrm{NH}_{4} \mathrm{NO}_{3}$ somehow alters the development of 
the root hairs so that they are unable to curl (Heidstra et al., 1994). The former possibility was eliminated when the $\mathrm{NH}_{4} \mathrm{NO}_{3}$ treatment was shown not to block induction by the Nod factor of the VsLbl gene, which is one of the earliest events in the root hair's response to rhizobial infection (Heidstra et al., 1997).

\section{Cluster roots}

Roots of some plant species adapted for growth on nutrient-poor soils are able to develop unusual bottlebrush-like structures consisting of discrete root segments flanked by densely packed clusters of short lateral roots (rootlets) (Skene, 2000; Skene, this volume). Often called proteoid roots because of their association with the family Proteaceae, cluster roots have also been reported in half a dozen other families of plants, including the Leguminoseae (Watt and Evans, 1999). A cluster root is distinct from a normal root in that the numerous rootlets are closely packed, develop only within distinct segments of the parent root $(0.5-1 \mathrm{~cm}$ long $)$ and all grow to a similar length. The rootlets are determinate and when they reach their final length the meristem is lost and root hairs develop all the way to the tip. Like normal lateral roots, the rootlets initiate from the pericycle. Cluster roots not only massively increase the surface area of the root for little additional investment in root biomass (in a similar way to root hairs), they also help to mobilize $\mathrm{P}$ and $\mathrm{Fe}$ by exuding high concentrations of organic acids (mainly citrate) into the rhizosphere.

Cluster roots are usually associated with $\mathrm{P}$ - or $\mathrm{Fe}-$ deficient soils, and both the numbers of cluster roots and their structure (rootlet length and density) are variable according to the extent of deficiency (Watt and Evans, 1999). Although one legume species (Lupinus consentinii) will form cluster roots under either $\mathrm{Fe}$ or $\mathrm{P}$ deficiency, it is more usual that plants responsive to $\mathrm{Fe}$ deficiency are not responsive to $\mathrm{P}$ deficiency and vice versa (Watt and Evans, 1999). Some species (e.g., white lupin, L. albus) are less sensitive to the presence of $\mathrm{P}$ in the soil and will produce some cluster roots even at $\mathrm{P}$ levels found in fertile agricultural soils (Keerthisinghe et al., 1998). When the ability of other nutrient stresses to stimulate cluster root formation in white lupin was tested, it was found that a $-\mathrm{Mn}$ treatment had a small stimulatory effect, while $-\mathrm{N},-\mathrm{K}$ and -Fe had none (Johnson et al., 1994).

\section{Distinguishing between external and internal nutritional signals}

There appear to be at least two ways by which plants monitor their nutrient supply: directly through localized changes in nutrient concentration in the external soil solution, or indirectly through changes in the internal nutrient status of the plant itself (Fig. 1). The direct pathway has the advantage that it can allow the plant to respond to short-term changes in nutrient availability and can in effect provide the roots with spatial information about the distribution of nutrients within the soil profile, allowing it to concentrate its developmental responses to that region of the soil where they will be of most benefit for nutrient acquisition. The indirect pathway has the advantage that it enables the plant to integrate its nutritional signals with those coming from range of other physiological processes (such as photosynthesis). In this section we will consider on a case-by-case basis the evidence for the existence of each of these regulatory pathways.

\section{Root growth and branching}

The localized proliferation of roots within nutrientrich soil patches is the clearest and best-documented example of a developmental response to an external nutrient supply. As discussed above, this response consists of an increased rate of lateral root elongation, sometimes accompanied by stimulation of lateral root initiation, specifically in regions of the root in contact with the enriched nutrient source (usually $\mathrm{N}$ or P). However, it is evident that root branching is also under some form of systemic control, i.e., it is not only dependent on the prevailing external nutrient concentration but also on the nutrient status of the plant as a whole. This is seen for example in the experiments of Drew et al. (1973), where the number of first-order lateral roots in the middle section of the barley root was markedly reduced if the top and bottom sections were supplied with $1 \mathrm{mM} \mathrm{NO}_{3}{ }^{-}$rather than $0.01 \mathrm{mM} \mathrm{NO}_{3}{ }^{-}$. Similarly, split root experiments with Douglas fir (Pseudotsuga menziesii) seedlings showed that when the plants were $\mathrm{N}$-stressed (by depriving the major part of the root of $\mathrm{N}$ ) the extent of root branching in the $\mathrm{N}$-rich zone was enhanced twofold compared to unstressed plants (Friend et al., 1990).

Recent experiments with Arabidopsis have thrown light on one possible mechanism by which the internal $\mathrm{N}$ status of the plant may modulate root branching (Zhang and Forde, 1998; Zhang et al., 1999). Roots 


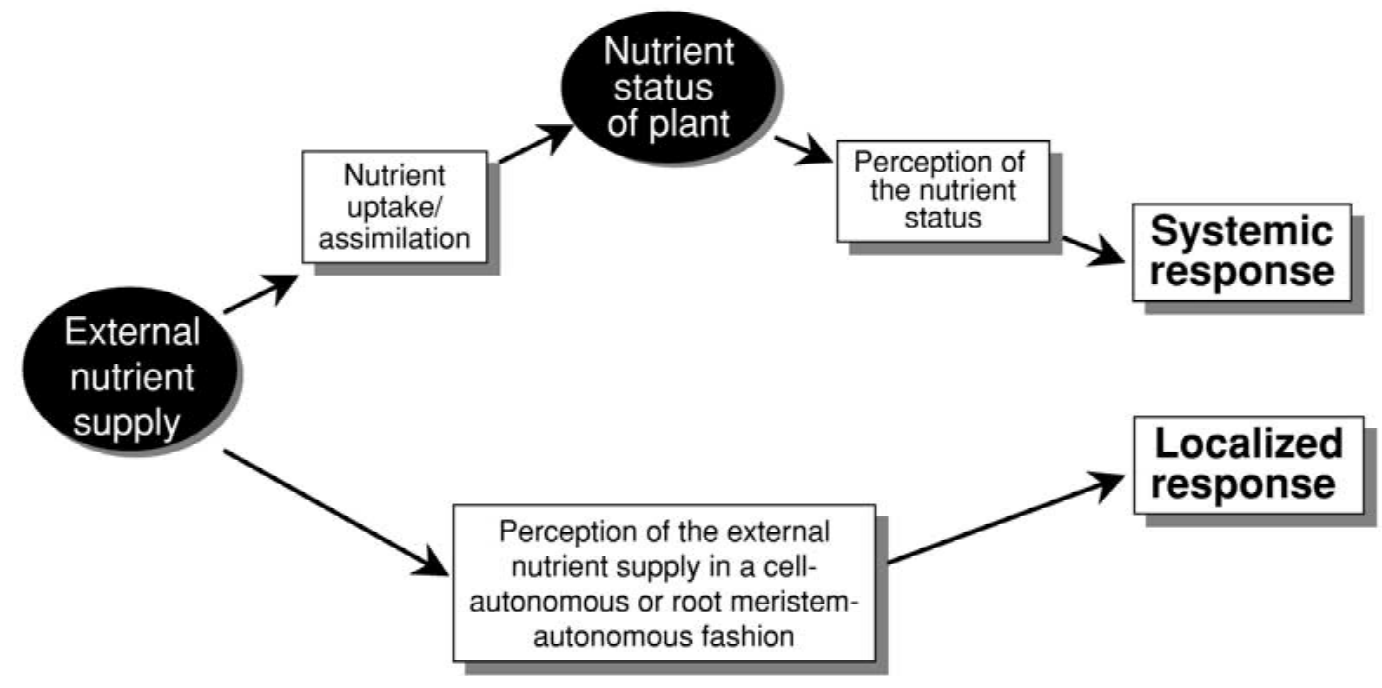

Figure 1. Alternative pathways for nutritional control of plant development.

of Arabidopsis seedlings growing on agar plates were uniformly supplied with a range of $\mathrm{KNO}_{3}$ concentrations $(0.01-50 \mathrm{mM})$ and the effects on root growth and branching analysed. Concentrations in the range $1-50 \mathrm{mM}$ had no significant effect on elongation of either primary roots or mature lateral roots. However, these high $\mathrm{NO}_{3}{ }^{-}$concentrations led to a marked reduction in the number of visible lateral roots. Detailed microscopic examination of the early stages of lateral root development at $1-50 \mathrm{mM} \mathrm{NO}_{3}{ }^{-}$revealed that the high rates of $\mathrm{NO}_{3}{ }^{-}$supply were having no effect on lateral root initiation itself, but rather were causing a pronounced delay in lateral root development at around the time of emergence from the parent root. The result was the appearance of stunted lateral roots $<0.5 \mathrm{mM}$ in length. The numbers of stunted lateral roots increased progressively as the $\mathrm{NO}_{3}{ }^{-}$concentration was increased above $1 \mathrm{mM}$, so that by $50 \mathrm{mM}$ (a concentration higher than would normally be found in soils) almost $100 \%$ were stunted.

If the lateral roots were allowed to progress up to or beyond the point of emergence before the plants received the $50 \mathrm{mM} \mathrm{NO}_{3}{ }^{-}$treatment, there was no effect on their growth (Zhang et al., 1999), demonstrating that there is a very specific stage of lateral root development which is sensitive to the high rate of $\mathrm{NO}_{3}{ }^{-}$supply. These stunted lateral roots were only temporarily blocked: if the experiment was extended for a further 7 days or so many of them had matured and were elongating at normal rates. This effect of $\mathrm{NO}_{3}{ }^{-}$appears to be a systemic rather than a localized one: when the $50 \mathrm{mM} \mathrm{NO}_{3}^{-}$was applied locally to just one part of the primary root it had a much smaller inhibitory effect than when it was applied to the whole root system, and this inhibitory effect was not restricted to the zone of treatment (Zhang et al., 1999).

The effect of high rates of $\mathrm{NO}_{3}{ }^{-}$supply on lateral root development seems to be related to the internal $\mathrm{NO}_{3}{ }^{-}$pool. This is indicated by the finding that a nitrate reductase (NR) deficient mutant (nialnia2) was more sensitive than the wild-type to the presence of high external concentrations of $\mathrm{NO}_{3}{ }^{-}$, i.e., the mutant produced a higher proportion of stunted lateral roots at a given $\mathrm{NO}_{3}{ }^{-}$concentration (Zhang et al., 1999). There may be analogies here with experiments previously done with low NR lines of tobacco: accumulation of $\mathrm{NO}_{3}{ }^{-}$in the shoots of these lines leads to much higher shoot:root ratios than in N-sufficient wild-type plants, even though the low NR lines are severely deficient in organic N (Scheible et al., 1997b). As in Arabidopsis, the effect appeared to be mainly due to a decrease in the numbers of lateral roots (Stitt and Feil, 1999), but unfortunately it was not established whether lateral root initiation or some later stage of lateral root development was affected in the tobacco plants. Split root experiments had previously established that the inhibition of root growth due to $\mathrm{NO}_{3}{ }^{-}$accumulation in the low NR lines was systemic and therefore likely to involve a shoot-derived signal (Scheible et al., 1997a).

It therefore appears that $\mathrm{NO}_{3}{ }^{-}$regulates root branching in both a localized and a systemic manner: its external presence stimulates the elongation of those mature lateral roots in direct contact with it (and in 
some cases lateral root initiation as well), while its accumulation inside the plant to concentrations above a certain threshold leads to a reduction in the numbers of mature lateral roots. This general pattern of response seems to apply to a wide range of species (from Arabidopsis to Douglas fir), although whether the details are always the same as in Arabidopsis remains to be established.

\section{Root diameter}

Localized signals may be responsible for modulating root diameter. When wheat or barley roots were subjected to a localized treatment with $\mathrm{NO}_{3}{ }^{-}$, the lateral roots growing in the $\mathrm{NO}_{3}{ }^{-}$-rich zone were significantly thicker than those not exposed to $\mathrm{NO}_{3}{ }^{-}$(Drew et al., 1973; Hackett, 1972). It has been noted that there is a positive correlation between root diameter and root elongation rate (Cahn et al., 1989; Thaler and Pages, 1996), so that the changes in root diameter observed in the $\mathrm{NO}_{3}{ }^{-}$-rich zone could be causally linked to the localized stimulation of lateral root elongation. There may be other regulatory mechanisms affecting the specific root length independently of growth rate, and perhaps these could operate systemically.

\section{Root angle}

Split-root experiments with bean showed that the decreased growth angle of the basal roots is a systemic response to low $\mathrm{P}$ : both 'low $\mathrm{P}$ ' and 'high $\mathrm{P}$ ' roots in a split-root system had growth angles similar to those in high P only (Bonser et al., 1996).

\section{Root hairs}

Again using split roots, evidence has been obtained that root hair growth is correlated not with the $\mathrm{P}$ or $\mathrm{NO}_{3}{ }^{-}$concentration outside the roots but rather with the internal $\mathrm{P}$ or $\mathrm{N}$ status of the plant (Foehse and Jungk, 1983). The additional finding that an alternative source of $\mathrm{N}$ (in the form of $\mathrm{NH}_{4}{ }^{+}$) did not affect root hair formation might suggest that internal $\mathrm{NO}_{3}{ }^{-}$ pools were more relevant to root hair growth than the pools of other N metabolites (Foehse and Jungk, 1983).

In a developmental study with Arabidopsis seedlings it was found that the differences between root hair length in 'low $\mathrm{P}$ ' and 'high $\mathrm{P}$ ' plants did not show up until 6 days after germination, after which the newly developed root hairs became progressively longer in the 'low $\mathrm{P}$ ' plants and progressively shorter in the 'high P' plants (Bates and Lynch, 1996). This would again seem to be most consistent with an effect of the internal $\mathrm{P}$ content of the seedlings rather than the external $\mathrm{P}$ concentration. However, the same study provided contradictory evidence that was more consistent with a localized effect of the external $\mathrm{P}$ concentration: when the tip of a 'low $\mathrm{P}$ ' root was treated with a high $\mathrm{P}_{i}$ concentration it inhibited root hair growth specifically within the 'high P' zone, while the reverse experiment (treating the tip of a 'high P' root with low $\mathrm{P}_{i}$ ) stimulated it. Perhaps both systemic and localized pathways contribute to the regulation of root hair growth in Arabidopsis.

\section{Nodulation}

Wilson (1917) reported that nodule formation in soybean was inhibited only in those parts of the root directly exposed to the $\mathrm{NO}_{3}{ }^{-}$supply. The conclusion that the inhibition of nodulation is primarily a localized response to $\mathrm{NO}_{3}{ }^{-}$has since been confirmed in a number of different studies (for review, see Carroll and Mathews, 1990). Nevertheless, some systemic effect of $\mathrm{NO}_{3}{ }^{-}$on nodulation has not been completely ruled out. When the $\mathrm{NO}_{3}{ }^{-}$concentration supplied to the $\mathrm{NO}_{3}{ }^{-}$-fed half of the split-root system is sufficiently high, nodule development in the $\mathrm{NO}_{3}{ }^{-}$-free half can be inhibited (Carroll and Gresshoff, 1983; Hinson, 1975). Other evidence for systemic effects of $\mathrm{NO}_{3}{ }^{-}$came from experiments in which $\mathrm{NO}_{3}{ }^{-}$was supplied either above or below the site of inoculation and was still effective in inhibiting nodulation (Malik et al., 1987). Since there is genetic evidence for a relationship between autoregulation of nodulation (a systemic phenomenon) and $\mathrm{NO}_{3}{ }^{-}$inhibition of nodulation (Day et al., 1989), it may be that $\mathrm{NO}_{3}{ }^{-}$interacts with the autoregulatory process at more than one level, accounting for both localized and systemic effects (see below).

\section{Cluster roots}

There is only a limited amount of information about the relative contribution of localized and systemic signals in regulating cluster root formation. Cluster roots tend to be most abundant in parts of the soil richest in organic matter (Watt and Evans, 1999), but this could be due to the higher water content of such patches rather than localized nutrient supplies per se. On the other hand, proteoid root formation in white lupin and $M$. cerifera was suppressed by foliar application of 
P (Dinkelaker et al., 1995), suggesting the importance of the $\mathrm{P}$ status of the plant and a likely role for systemic signals in modulating cluster root formation. This conclusion is supported by a recent study in which phosphonate $\left(\mathrm{HPO}_{3}{ }^{2-}\right)$ was used as a tool to investigate the role of internal $\mathrm{P}$ status in regulating proteoid root development (Gilbert et al., 2000). Phosphonate is an analogue of inorganic phosphate that is reported to interfere with plant perception of internal $\mathrm{P}$ concentration (Carswell et al., 1997). Treatment of Psufficient white lupin plants with phosphonate led to a dramatic increase in the number cluster roots, and the induced rootlets displayed the full repertoire of physiological changes associated with proteoid root development (Gilbert et al., 2000). Unfortunately, progress in elucidating the molecular mechanisms involved in regulating cluster root formation is being hampered by the lack of suitable well-characterized genotypes and mutants of the relevant species.

\section{Mechanisms}

In this section we review our state of knowledge about the mechanisms by which nutrients can exert both localized and systemic effects on developmental processes in roots.

\section{Localized responses}

The fact that many of the ions that are able to stimulate localized developmental responses in the root are highly mobile within the plant (Marschner, 1995) would argue against a simple 'first-come first-served' model whereby the cells or roots in the immediate vicinity of the nutrient patch benefit most from its presence. On the other hand, the apparent hydraulic isolation of the root apex from the rest of the root due to lack of maturity of the xylem within the apical zone (Melcior and Steudle, 1993), could mean that the meristematic zone is dependent to at least some degree on external ions, providing a possible explanation for localized stimulation of root growth. However, a model of this kind would make it difficult to account for why the stimulatory effect is specific to certain ions (see above) and why it acts on lateral roots but not on primary roots.

Another explanation for localized lateral root proliferation was prompted by the observation that localized supplies of various nutrients (including $\mathrm{NO}_{3}{ }^{-}$ and $\mathrm{P}$ ) are associated with increased respiration rates in maize roots exposed to the nutrient patch (Sattelmacher and Thoms, 1995). It was proposed that the increased metabolic activity at the site of nutrient uptake creates a stronger sink for photosynthate from the shoot, and that the enhanced phloem unloading brings with it an influx of phytohormones (such as auxin) which promote root growth. However, an immediate difficulty with this model is the finding that a localized $\mathrm{K}^{+}$supply also stimulates respiration but does not affect root growth (Sattelmacher and Thoms, 1995).

In recent years we have begun to develop a greater appreciation of the remarkable sophistication of the nutrient sensing mechanisms available to both prokaryotic and eukaryotic cells. Bacteria use members of the family of two-component regulators to sense changes in their environment. For example the Escherichia coli narX and narQ genes encode transmembrane histidine kinases which act as external $\mathrm{NO}_{3}{ }^{-}$receptors and, in the presence of external $\mathrm{NO}_{3}{ }^{-}$or $\mathrm{NO}_{2}{ }^{-}$, activate transcription factors encoded by the narL and narP genes respectively (Merrick and Edwards, 1995). In budding yeast (Saccharomyces cerevisiae), transmembrane sensors for glucose, amino acids and $\mathrm{NH}_{4}{ }^{+}$have been identified and found to be homologous to membrane proteins that act as transporters for the respective nutrients (Klasson et al., 1999; Lorenz and Heitman, 1998; Ozcan et al., 1996).

Although no analogous nutrient sensors have so far been identified in plants, there is good reason to believe that they do exist. An external supply of $\mathrm{NO}_{3}{ }^{-}$ is able to trigger the rapid induction of a number of genes including those for NR, nitrite reductase and $\mathrm{NO}_{3}{ }^{-}$transporters. It has been shown that NR activity is not required for the induction to occur, clearly implicating the $\mathrm{NO}_{3}{ }^{-}$ion as the signal molecule (Deng et al., 1989; Pouteau et al., 1989). A number of lines of evidence suggest that the external presence of even very low $\mathrm{NO}_{3}{ }^{-}$concentrations $(<10 \mu \mathrm{M})$ can be sensed by plant roots (reviewed in Forde and Clarkson, 1999). Using NR-deficient mutants it has been shown that $\mathrm{NO}_{3}{ }^{-}$stimulation of lateral root elongation in Arabidopsis (Zhang and Forde, 1998) and localized $\mathrm{NO}_{3}{ }^{-}$inhibition of nodulation in legumes (Carroll and Gresshoff, 1986; Jacobsen, 1984) are both independent of $\mathrm{NO}_{3}{ }^{-}$assimilation. In the former case the key role of the $\mathrm{NO}_{3}{ }^{-}$ion was confirmed by the finding that localized supplies of other $\mathrm{N}$ sources $\left(\mathrm{NH}_{4}{ }^{+}\right.$and glutamine) could not substitute for $\mathrm{NO}_{3}{ }^{-}$(Zhang et al., 1999).

With this background it seems not unreasonable to propose that the localized developmental responses to 
$\mathrm{NO}_{3}{ }^{-}$(and probably to other nutrient ions as well) are also mediated via specific sensors or receptors on the plasma membrane (or elsewhere) and their associated signal transduction pathways. This would predict the existence of nutritionally regulated transcription factors or other regulatory proteins that could modulate developmental processes in response to changes in the external nutrient supply. A candidate for just such a protein was recently identified in the form of a root-specific and $\mathrm{NO}_{3}{ }^{-}$-inducible member of the MADS-box family of transcription factors which is encoded in Arabidopsis by the ANRl gene (Zhang and Forde, 1998). Other members of the MADS-box family in plants are key regulators of floral organogenesis (Shore and Sharrocks, 1995) and evidence was obtained using antisense and co-suppressed lines that the ANRl gene is required for $\mathrm{NO}_{3}{ }^{-}$stimulation of lateral root elongation (Zhang and Forde, 1998).

A second Arabidopsis gene (AXR4) has also been implicated in the signalling mechanism linking external $\mathrm{NO}_{3}{ }^{-}$to increased rates of lateral root elongation. AXR4 was originally identified in a screen for mutants in which root growth was less sensitive to auxin (Hobbie and Estelle, 1995). Root gravitropism is defective in the axr4 mutants, but otherwise they display few of the pleiotropic effects associated with other auxin-resistant mutants. When several auxinresistant mutants were tested for the ability of their lateral roots to respond to localized $\mathrm{NO}_{3}{ }^{-}$supplies, only axr4 was found to be significantly defective (Zhang et al., 1999). This suggests that there is an overlap between the signal transduction pathways for auxin and $\mathrm{NO}_{3}{ }^{-}$signalling, but unfortunately the nature of the $A X R 4$ gene product is as yet unknown. A recent model for the signal transduction pathway linking external $\mathrm{NO}_{3}{ }^{-}$to increased rates of cell production in the lateral root tip is shown in Fig. 2.

There are some parallels between $\mathrm{NO}_{3}{ }^{-}$stimulation of lateral root growth and $\mathrm{NO}_{3}{ }^{-}$inhibition of nodulation. As discussed above, $\mathrm{NO}_{3}{ }^{-}$inhibition of nodulation is also (at least partly) a localized effect, and evidence from the use of NR-deficient mutants of pea and soybean indicates that here too the $\mathrm{NO}_{3}{ }^{-}$ ion itself is able elicits the response (Carroll and Gresshoff, 1986; Jacobsen, 1984).

Mutants of both pea and soybean have been isolated which are $\mathrm{NO}_{3}{ }^{-}$-tolerant for nodulation (Carroll et al., 1985; Postma et al., 1988) and these have helped to shed some light on the mechanism of $\mathrm{NO}_{3}{ }^{-}$inhibition. All $\mathrm{NO}_{3}{ }^{-}$-tolerant mutants isolated so far are defective in the autoregulatory mechanism (and so also display a 'supernodulating' phenotype), and grafting experiments have shown that in most cases the mutant phenotype is controlled by the shoot (Carroll and Mathews, 1990; Delves et al., 1987; Francisco and Akao, 1993). This suggests that $\mathrm{NO}_{3}{ }^{-}$inhibition of nodulation acts through an interaction with the autoregulatory mechanism, which is thought to depend on the production of a phloem-mobile inhibitory signal (of unknown nature) in the shoot (Carroll and Mathews, 1990). A model has been proposed in which external $\mathrm{NO}_{3}{ }^{-}$acts by potentiating the effects of this autoregulatory signal in those parts of the root directly exposed to the $\mathrm{NO}_{3}{ }^{-}$(Gresshoff et al., 1988).

Intriguingly all the $\mathrm{NO}_{3}{ }^{-}$-tolerant nodulation mutants also have an altered root phenotype (increased numbers of lateral roots and an increased shoot:root ratio), even when uninoculated with rhizobium (Day et al., 1986; Postma et al., 1988). In this respect the $\mathrm{NO}_{3}{ }^{-}$-tolerant mutants have a constitutive 'high N' phenotype. It is therefore possible that the regulatory mechanisms responsible for autoregulation and $\mathrm{NO}_{3}{ }^{-}$regulation of nodulation have evolved from preexisting mechanisms for regulation of root development and shoot:root partitioning that may be common to non-legumes. In this regard it is interesting that an alfalfa gene (NMHC5) which belongs to the same subfamily of MADS-box genes as ANRI (the AGL17 subfamily) is expressed specifically in nodules (Heard et al., 1997). The function of the NMHC5 gene product is so far unknown.

Another gene with a potential role in $\mathrm{N}$ regulation of nodulation has recently been identified in Lotus japonicus (Schauser et al., 1999). This gene (Nin), which is required for the formation of infection threads and the initiation of nodule primordia, encodes a putative transcription factor with homology to the Mid protein in Chlamydomonas. Mid is a developmental regulator involved in determining mating type during gametogenesis (Ferris and Goodenough, 1997), and since gametogenesis in Chlamydomonas is induced by $\mathrm{N}$ limitation it has been postulated that Nin might play a role in $\mathrm{N}$ regulation of nodulation(Schauser et al., 1999). Recently it was shown that $\mathrm{NO}_{3}{ }^{-}$inhibited gametogenesis and the expression of two gamete-specific genes even in NR-deficient mutants of Chlamydomonas, indicating that the $\mathrm{NO}_{3}{ }^{-}$ ion itself is providing the negative regulatory signal for the sexual differentiation of the alga (Pozuelo et al., 2000). Thus Mid in Chlamydomonas and Nin in L. japonicus might be components of related signal transduction pathways that link the external $\mathrm{NO}_{3}{ }^{-}$ 


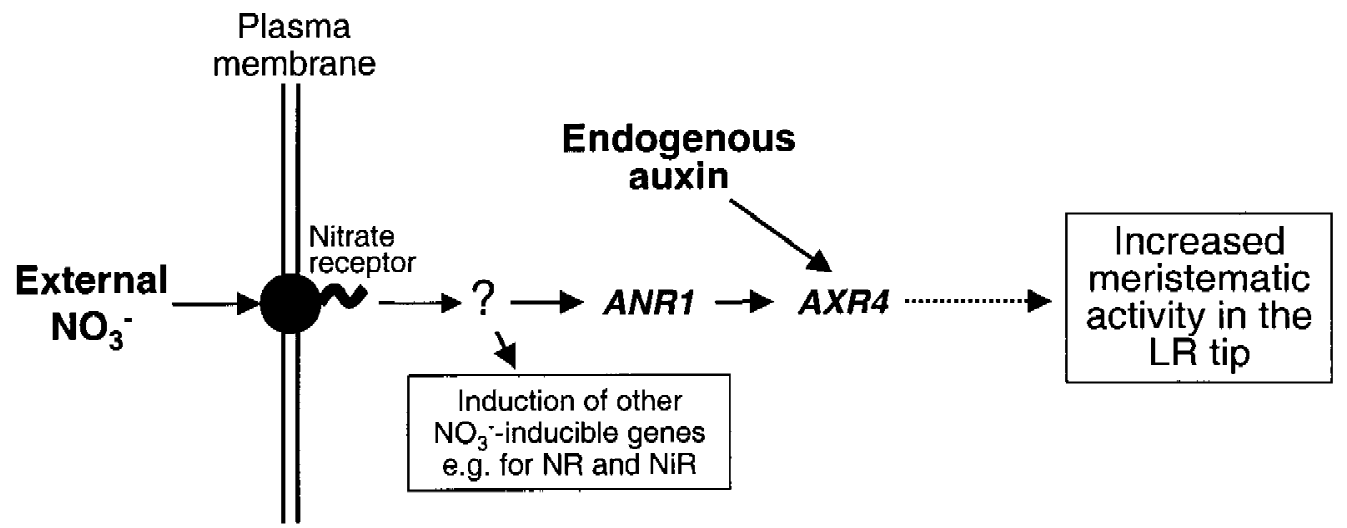

Figure 2. Model for the signalling pathway for $\mathrm{NO}_{3}{ }^{-}$regulation of lateral root growth. The question mark refers to the as yet uncharacterised part of the signalling pathway responsible for $\mathrm{NO}_{3}{ }^{-}$induction of gene expression. Diagram modified from Zhang et al. (1999). See text for further details.

\section{A. Localized effects}

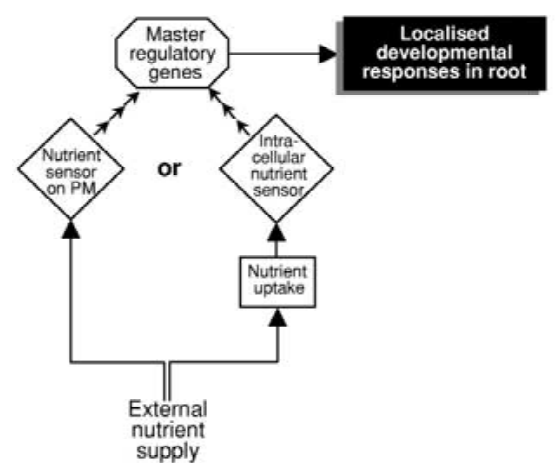

\section{B. Systemic effects}

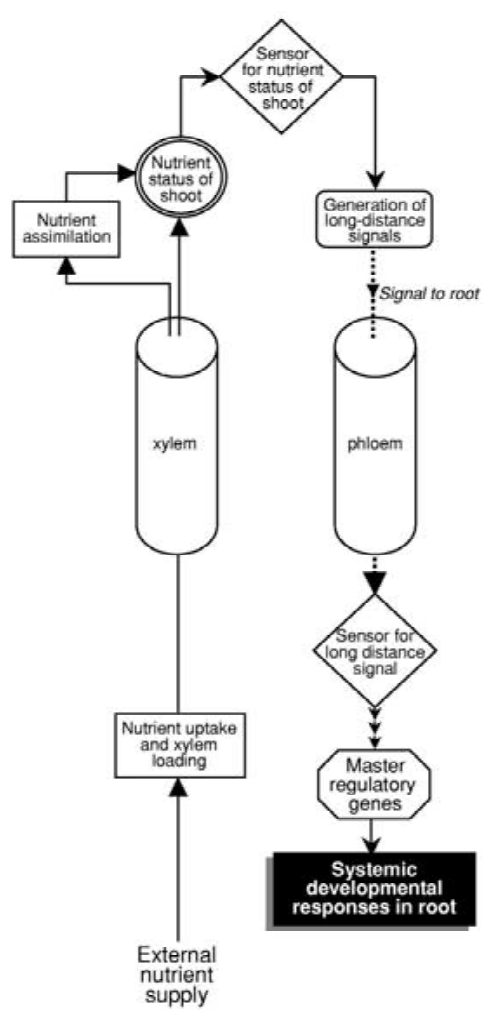

Figure 3. Generalised models for signalling pathways involved in (A) the localized and (B) the systemic responses to the nutrient supply. The existence of master regulatory genes that modulate the relevant developmental processes is proposed. These would also be subject to modulation by any other environmental signals to which those developmental processes were susceptible, and would therefore serve to integrate the plant's responses to multiple inputs. 
supply to the negative regulation of two very different developmental pathways.

A generalized model for how an external nutrient supply may exert localized effects on developmental processes in roots is presented in Fig. 3A. Although it seems most likely that the external nutrient concentration is monitored directly by means of sensors or receptors in the plasma membrane of root epidermal or cortical cells (Forde and Clarkson, 1999), it is difficult to rule out the possibility that there are sensors inside these cells which are able to detect fluctuations in intracellular nutrient concentrations that occur in parallel with changes in the external supply.

\section{Systemic responses}

Where the root's response to the nutrient supply is systemic it appears that sensing of the plant's nutrient status takes place in the shoot and that the shoot is then the source of long-distance signals that regulate both physiological and developmental processes in the root. This raises a series of questions that as yet have few clear answers. How, at the molecular level, is the nutrient status of the shoot monitored? What key ions or metabolites are being monitored? What is the nature of the shoot-to-root signals? How are these signals perceived in the root? The fact that many nutritional responses are specific to particular nutrients indicates that the plant is able to monitor many different nutrients independently and to transmit nutrient-specific regulatory signals to the root.

Much of the effort to date in elucidating the mechanism of shoot-to-root signalling of nutrient status has been based on the physiological responses rather than the developmental ones. For example, the evidence that the uptake of inorganic ions by roots is regulated in accordance with the shoot's demand for the ions (Marschner, 1995), has led to a search for the means by which the shoot can communicate its requirements to the transport systems of the root. For N, it has been proposed that the rapid cycling of amino acids which occurs between shoot and root would serve to provide the root with the necessary information about changes in the shoot's N status (Cooper and Clarkson, 1989; Imsande and Touraine, 1994). However, contrary to the requirements of this model it is sometimes found that $\mathrm{N}$ deficiency can lead to an increase rather than a decline in amino acid cycling (e.g., Peuke et al., 1994). Furthermore, two detailed split-root studies on oil-seed rape and mung bean (Ricinus communis) confirmed that rates of $\mathrm{NO}_{3}{ }^{-}$uptake were strongly correlated with the shoot $\mathrm{N}$ content, but found no correlation with either the amino acid content of the root (Lainé et al., 1995; Tillard et al., 1998) nor with quantitative or qualitative changes in the amino acid content of the phloem (Tillard et al., 1998). Thus although it is possible that transient changes in phloem amino acid content could be missed, amino acid cycling seems unlikely to provide the shoot-derived signal that regulates either $\mathrm{NO}_{3}{ }^{-}$uptake or root development. In agreement with this, the decreased root growth found in NR-deficient tobacco lines is actually accompanied by an increase in the amino acid content of the roots (Scheible et al., 1997b). As yet there is no alternative candidate for the $\mathrm{N}$ signal.

The cloning of a gene encoding a chloroplast homologue of the bacterial $\mathrm{P}_{I I}$ protein has provided a possible candidate for a component of the $\mathrm{N}$ sensing machinery in Arabidopsis shoots (Hseih et al., 1998). In E. coli and other bacteria, $\mathrm{P}_{I I}(\mathrm{GlnB})$ is part of the regulatory pathway that controls transcription of a number of $\mathrm{N}$ assimilatory genes in response to cellular N status (Merrick and Edwards, 1995). However, the Arabidopsis $\mathrm{P}_{I I}$-like protein is localized within the chloroplast, and there may well be separate and distinct $\mathrm{N}$ regulatory pathways of a eukaryotic type which operate in the cytosol.

There is even less information about the mechanisms for monitoring and responding to the internal supplies of other nutrients. The phol mutant of Arabidopsis, which is defective in $\mathrm{P}_{i}$ transport to the shoot, has been used to demonstrate that P-regulated genes in the root are responding not to Pi levels in the root but to the P status of the shoot (Bariola et al., 1994; Burleigh and Harrison, 1999). Whether the signal from the shoot is Pi itself arriving in the phloem or some other metabolite or signal molecule has yet to be established.

There is good evidence that Fe-deficiency responses in the root are controlled at least in part by shoot-derived signals (Schmidt, 1999), and it appears that the signal coming from the shoot is not Fe itself. The latter conclusion was based on grafting experiments using an Fe over-accumulating mutant $(d g l)$ of pea which indicated that the $d g l$ shoot was constitutively producing a signal compound of an unknown kind that was acting to stimulate $\mathrm{Fe}$ (III) reductase activity in the root (Grusak and Pezeshgi, 1996). A role for the non-protein amino acid nicotianamine (an efficient chelator of $\mathrm{Fe}(\mathrm{II})$ and $\mathrm{Fe}(\mathrm{III})$ ) in sensing of internal $\mathrm{Fe}$ status has been hypothesized based on the Fe-overaccumulating phenotype of a 
nicotianamine-deficient tomato mutant (chloronerva) (Scholz et al., 1992). In addition, the root system of the recessive tomato mutant $\mathrm{fer}$ is unable to induce any of the characteristic responses to Fe deficiency (Bienfait, 1988; Ling et al., 1996) and the Fer gene product is thought to be a component of the Fe sensing or regulatory system responsible for induction of genes that mediate the Fe-deficiency responses (for a more detailed discussion of Fe sensing in plants and other organisms see Schmidt, 1999)

Fig. 3B shows a generalized model for systemic regulation of developmental processes in the root by means of long distance signals from the shoot.

\section{Integrating localized and systemic responses}

An important question is how the systemic and localized signals discussed above are integrated within the plant to produce the observed developmental responses. One way of integrating the different signals would be if the master regulatory genes depicted in Fig. 3A, B were the same, so that the localized and systemic signalling pathways converge. Something of this kind has been postulated for $\mathrm{NO}_{3}{ }^{-}$regulation of nodulation (Gresshoff et al., 1988), where a localized $\mathrm{NO}_{3}{ }^{-}$signal is proposed to interact with the systemic autoregulatory signal emanating from the shoot (see above). Cross-talk or convergence between different signal transduction pathways is becoming a well-established mechanism in plants by which signals from independent stimuli are integrated at the biochemical and genetic levels (Genoud and Métraux, 1999).

It is also possible for the systemic and localized signals to act on different stages of the developmental process, so that integration may only be achieved at the whole plant level. An example is seen in the effects of $\mathrm{NO}_{3}{ }^{-}$on root branching in Arabidopsis (Zhang et al., 1999). As discussed in detail above, it appears that the stimulatory effect of a localized $\mathrm{NO}_{3}{ }^{-}$acts mainly on elongation of mature lateral roots, while the systemic inhibitory effect of high $\mathrm{NO}_{3}{ }^{-}$status acts specifically on immature, emerging lateral roots.

\section{Alternatives to nutrients and their metabolites as long-distance signals}

The above survey would argue against a direct role for nutrients or their metabolites in communicating information to the root about the shoot's nutrient status.
An alternative hypothesis would be that the shoot has mechanisms for monitoring the supply of certain key ions or metabolites, and then for modulating the production of phloem-mobile signal(s) that are perceived in the root and converted into appropriate metabolic and developmental responses (see Fig. 3B). What might those phloem-mobile signals be? Auxin is synthesized in the shoot and carried in the phloem, but given the specificity of the root's responses to changes in the supply of particular nutrients it is difficult to envisage how auxin on its own (or any of the other 'conventional' plant hormones) could confer that specificity.

In recent years it has become clear that the phloem carries a number of different classes of macromolecules (proteins and RNAs) which are potentially capable of transmitting long distance signals within the plant (Citovsky and Zambryski, 2000; Thompson and Schulz, 1999). A well-characterized example of a phloem-mobile peptide signal is systemin, a peptide involved in triggering systemic acquired resistance to pathogens, which is synthesized within the infected leaf and moved around the plant via the phloem (Ryan, 2000). A model has been proposed in which the nutrient and water status of the shoot is communicated to the root by means of proteinaceous signal molecules (Lucas, 1997). Evidence that a specific population of mRNA molecules circulate throughout the plant via the phloem has been obtained from studies on pumpkin (Cucurbita maxim) (Ruiz-Medrano et al., 1999). One particular species of mRNA (CmNACP), which is selectively translocated in the phloem, belongs to the 'NAC domain' gene family, some of whose members are involved in controlling apical meristem development. The hypothesis was therefore put forward that the phloem may act as an 'information superhighway', carrying signals in the form of phloem sap-specific mRNAs (or their encoded proteins) to enable developmental events in the various meristems of the plant to be integrated with physiological processes in the leaves (Ruiz-Medrano et al., 1999). These findings open up exciting new possibilities for how the shoot might be able to communicate its nutritional requirements to the root in highly specific ways.

\section{Role of hormones in the response to nutrient supply}

It is frequently observed that the plant's responses to changes in nutrient supply can be mimicked by exo- 
genously applying a particular plant hormone. The conclusion then tends to be drawn that the hormone in question must play an important role in mediating the nutritional effects. For example, auxin and ethylene have been linked to the Fe-deficiency response (Schmidt, 1999), abscisic acid (ABA) and ethylene have been implicated in the response to P stress (Lynch and Brown, 1997; Trull et al., 1997), a role for ethylene in $\mathrm{NO}_{3}{ }^{-}$suppression of nodulation has been proposed (Ligero et al., 1999) and auxin transported from the shoot is reported to play a role in stimulating the formation of proteoid roots in P-deficient white lupin plants (Gilbert et al., 2000).

However, the evidence in favour of a role for a particular hormone in these nutritional responses is frequently circumstantial, and in a number of important cases the contrary evidence is quite compelling. When two ABA mutants (abal and abi2) of Arabidopsis were analyzed for their developmental and physiological responses to $\mathrm{P}$ stress, they were found to be normal in most respects, implying that $\mathrm{ABA}$ does not have a major role in coordinating the $\mathrm{P}$ stress response (Trull et al., 1997). Schmidt et al. (2000) looked at the induction of Fe-deficiency symptoms (root hairs and ferric reductase activity) in 40 hormone-related mutants of Arabidopsis, including lines which were insensitive or resistant to auxin, cytokinin, ABA and ethylene. Both root hair formation and ferric reductase activity were enhanced by $\mathrm{Fe}-$ deficiency in all the mutants tested, making it difficult to argue a primary role for any of these hormones in the response. Furthermore, it was noted that the root hair response to applying the ethylene precursor ACC (1-aminocyclopropane-1-carboxylic acid) was qualitatively quite different from the root hair response to Fe-deficiency (Schmidt et al., 2000). The role of ethylene in $\mathrm{NO}_{3}{ }^{-}$suppression of nodulation is controversial. Several lines of evidence support a model in which $\mathrm{NO}_{3}{ }^{-}$acts by stimulating the production of ethylene, which then inhibits nodulation (Ligero et al., 1991, 1999). However, other workers have failed to confirm that ethylene inhibits nodulation in soybean (Hunter, 1993; Lee and La Rue, 1992), and experiments with ethylene-insensitive mutants of soybean found that they were equally sensitive to $\mathrm{NO}_{3}{ }^{-}$suppression of nodule numbers as the wild-type (Schmidt et al., 1999).

Since hormones such as auxin, cytokinin, ABA and ethylene play such an important part in all aspects of plant development and physiology, it would be surprising if they did not interact in some way with the nutritional effects discussed in this review. However, the evidence that nutrients modulate development by effecting changes in the levels of endogenous hormones is far from convincing. Nevertheless, it is becoming increasingly evident that signal transduction in plants involves extensive cross-talk between different signalling pathways (Genoud and Métraux, 1999). It is therefore likely that once signal transduction pathways for nutrients are elucidated they will be found to interact and intersect with hormonal response pathways. As we have seen (above and Fig. 2), evidence for this already exists in the case of $\mathrm{NO}_{3}{ }^{-}$stimulation of lateral root growth in Arabidopsis, where the AXR4 gene product appears to be a component of signalling pathways for both $\mathrm{NO}_{3}{ }^{-}$and auxin (Zhang et al., 1999).

\section{Conclusions}

It is clear that nutrients have profound effects on many aspects of root development. Furthermore, many of these effects are specific to particular nutrients and are strongly dependent on the genotype of the plant. In most cases, the developmental responses are adaptive, that is they serve to increase the efficiency of nutrient capture under situations of nutrient limitation, while minimizing on the input costs in terms of biomass (see Robinson, this volume). In these ways, the nutritional responses discussed in this review are quite distinct from simple growth responses or from non-specific effects such as might be associated with severe nutrient stress.

In general, the developmental processes that are sensitive to the nutrient supply are quantitatively modulated by it rather than being absolutely dependent on a particular nutritional signal. In this respect, nutritional regulation of development differs for example from the photomorphogenetic switch that occurs when dark-grown etiolated seedlings are exposed to light. However, there is a clearer parallel with another aspect of photomorphogenesis, the shade avoidance response, where the development of the shoot is modulated in a variety of quantitative ways by the direction and quality (red:far-red ratio) of the light source, enabling the plant to place its resource acquiring structures (leaves) in a more favourable position (Ballare, 1999). The shade avoidance response depends on the perception of the photons of different wavelengths by means of a family of photoreceptors known as phyto- 
chromes which are the first components of a complex signal transduction pathway (Furuya and Kim, 2000).

In view of the parallels with photomorphogenesis, and the accumulating evidence reviewed here that analogous pathways of signal perception and transduction are involved, we propose the term 'trophomorphogenesis' to describe changes in plant morphology arising from variations in the availability or distribution of nutrients in the environment. As we have seen from the above examples, the trophomorphogenic responses may be direct (localized responses resulting from changes in external nutrient concentration), or indirect (systemic responses resulting from changes in the plant's internal nutrient status), or sometimes a combination of the two. Straightforward growth responses not involving changes in plant morphology, and differences in plant morphology that could be attributed simply to effects of the nutrient supply on ontogenetic drift (see above), would naturally be excluded from this definition.

Clearly the picture presented in this review differs markedly from the conventional and still widely held view that developmental responses to the nutrient supply can be explained simply in terms of sourcesink relationships and the reallocation of carbohydrate within the plant. The models we put forward make predictions for the existence of specific sensors for internal and external nutrient pools, intracellular and inter-organ signalling pathways and master regulatory genes that help to integrate the plant's response to multiple environmental signals (Fig. 3). By analogy with the progress currently being made in identifying components of the phytochrome signalling pathway (Furuya and Kim, 2000), we expect that forward and reverse genetic approaches in Arabidopsis and other species will enable these models to be put to the test and will ultimately lead to the elucidation of the nutrient signalling pathways.

\section{Acknowledgements}

The authors are grateful to the three referees for their helpful and constructive comments. HL wishes to acknowledge financial assistance from the Foundation Dr. M. Morales, La Palma, Spain. Work in BGF's laboratory was partly supported by a grant from the European Union (contract number BIO4-CT972231) in the Biotech programme of Framework IV. IACR-Rothamsted receives grant-aided support from the BBSRC.

\section{References}

Ballaré C L 1999 Keeping up with the neighbours: phytochrome sensing and other signalling mechanisms. Trends Plant Sci. 4, 97-102.

Bariola P A, Howard C J, Taylor C B, Verburg M T, Jaglan V D and Green P J 1994 The Arabidopsis ribonuclease gene RNS1 is tightly controlled in response to phosphate limitation. Plant J. 6, 673-685.

Bates T R and Lynch J P 1996 Stimulation of root hair elongation in Arabidopsis thaliana by low phosphorus availability. Plant Cell Environ. 19, 529-538.

Bazzaz F A, Garbutt K, Reekie E G and Williams W E 1989 Using growth analysis to interpret competition between a $\mathrm{C} 3$ and a $\mathrm{C} 4$ annual under ambient and elevated $\mathrm{CO}_{2}$. Oecologia 79, 223-225.

Bhat K K S, Nye P H and Bereton A J 1979 The possibility of predicting solute uptake and plant growth responses from independently measured soil and plant characteristics. VI. The growth and uptake of rape in solutions of constant nitrate concentration. Plant Soil 53, 137-167.

Bienfait H F 1988 Proteins under the control of the gene for $\mathrm{Fe}$ efficiency in tomato. Plant Physiol. 88, 785-787.

Bilbrough C J and Caldwell M M 1995 The effects of shading and $\mathrm{N}$ status on root proliferation in nutrient patches by the perennial grass Agropyron desertorum in the field. Oecologia 103, 10-16.

Bonser A M, Lynch J and Snapp S 1996 Effect of phosphorus deficiency on growth angle of basal roots in Phaseolus vulgaris. New Phytol. 132, 281-288.

Boot R G A and Mensink M 1990 Size and morphology of root systems of perennial grasses from contrasting habitats as affected by nitrogen supply. Plant Soil 129, 291-299.

Burleigh S H and Harrison M J 1999 The down-regulation of Mt4like genes by phosphate fertilization occurs systemically and involves phosphate translocation to the shoots. Plant Physiol. 119, 241-248.

Cahn M D, Zobel R W and Bouldin D R 1989 Relationship between root elongation rate and diameter and duration of growth of lateral roots of maize. Plant Soil 119, 271-279.

Carroll B J and Gresshoff P M 1983 Nitrate inhibition of nodulation and nitrogen-fixation in white clover. Z. Pflanzenphysiol. 110, 77-88.

Carroll B J and Gresshoff P M 1986 Isolation and initial characterization of constitutive nitrate reductase-deficient mutants nr328 and nr345 of soybean (Glycine max). Plant Physiol. 81, 572-576.

Carroll B J and Mathews A 1990 Nitrate inhibition of nodulation in legumes. In Molecular Biology of Symbiotic Nitrogen Fixation. Ed. P M Gresshoff. pp 159-180. CRC Press, Boca Raton, FL.

Carroll B J, McNeil D L and Gresshoff P M 1985 Isolation and properties of soybean [Glycine $\max (\mathrm{L}$.) Merr] mutants that nodulate in the presence of high nitrate concentrations. Proc. Natl. Acad. Sci. USA. 82, 4162-4166.

Carswell M C, Grant B R and Plaxton W C 1997 Disruption of the phosphate-starvation response of oilseed rape suspension cells by the fungicide phosphonate. Planta 203, 67-74.

Chapin F S I 1980 The mineral nutrition of wild plants. Annu. Rev. Ecol. Syst. 11, 233-260.

Citovsky V and Zambryski P 2000 Systemic transport of RNA in plants. Trends Plant Sci. 5, 52-54.

Coleman J S, McConnaughay K D M and Ackerly D D 1994 Interpreting developmental variation in plants. Trends Ecol. Evol. 9, 187-191.

Cooper H D and Clarkson D T 1989 Cycling of amino nitrogen and other nutrients between shoots and roots in cereals: a pos- 
sible mechanism integrating shoot and root in the regulation of nutrient uptake. J. Exp. Bot. 40, 753-762.

Couot-Gastelier J and Vartanian N 1995 Drought-induced short roots in Arabidopsis thaliana: structural characteristics. Bot. Acta 108, 407-413.

Day D A, Lambers H, Bateman J, Carroll B J and Gresshoff P M 1986 Growth comparisons of a supernodulating soybean (Glycine max) mutant and its wild-type parent. Physiol. Plant. 68, 375-382.

Day D A, Carroll B J, Delves A C and Gresshoff P M 1989 Relationship between auto-regulation and nitrate inhibition of nodulation in soybeans. Physiol. Plant. 75, 37-42.

Delves A C, Higgins A V and Gresshoff P M 1987 Shoot control of supernodulation in a number of mutant soybeans, Glycine max (L.) Merr. Aust. J. Plant Physiol. 14, 689-694.

Deng M D, Moureaux T and Caboche M 1989 Tungstate, a molybdate analog inactivating nitrate reductase, deregulates the expression of the nitrate reductase structural gene. Plant Physiol. 91, 304-309.

Dinkelaker B, Hengeler C and Marschner H 1995 Distribution and function of proteoid roots and other root clusters. Bot. Acta 108, 183-200.

Drew M C 1975 Comparison of the effects of a localized supply of phosphate, nitrate, ammonium and potassium on the growth of the seminal root system, and the shoot, in barley. New Phytol. 75, 479-490.

Drew M C and Saker L R 1975 Nutrient supply and the growth of the seminal root system of barley. II. Localized, compensatory increases in lateral root growth and rates of nitrate uptake when nitrate supply is restricted to only part of the root system. J. Exp. Bot. 26, 79-90.

Drew M C and Saker L R 1978 Nutrient supply and the growth of the seminal root system in barley. III. Compensatory increases in growth of lateral roots, and in rates of phosphate uptake in response to a localized supply of phosphate. J. Exp. Bot. 29, 435451.

Drew M C, Saker L R and Ashley T W 1973 Nutrient supply and the growth of the seminal root system in barley. I. The effect of nitrate concentration on the growth of axes and laterals. J. Exp. Bot. 24, 1189-1202.

Ericsson T 1995 Growth and shoot:root ratio of seedlings in relation to nutrient availability. Plant Soil 168-169, 205-214.

Evans G C 1972 The Quantitative Analysis of Plant Growth. University of California Press.

Ferris P J and Goodenough U W 1997 Mating type in Chlamydomonas is specified by Mid, the minus dominance gene. Genetics 146, 859-869.

Fitter A H 1976 Effects of nutrient supply and competition from other species on root growth of Lolium perenne in soil. Plant Soil 45, 177-189.

Fitter A H 1985 Functional significance of root morphology and root system architecture. In Ecological Interactions in Soil, Special Publication of the British Ecological Society, No. 4. Ed. A H Fitter, D Atkinson, D J Read, and M B Usher. pp 87-106. Blackwell Scientific, Oxford.

Fitter A H 1987 An architectural approach to the comparative ecology of plant- root systems. New Phytol. 106 (Suppl), 61-77.

Foehse D and Jungk A 1983 Influence of phosphate and nitrate supply on root hair formation of rape, spinach and tomato plants. Plant Soil 74, 359-368.

Forde B G and Clarkson D T 1999 Nitrate and ammonium nutrition of plants: physiological and molecular perspectives. Adv. Bot. Res. 30, 1-90.
Francisco P B and Akao S 1993 Autoregulation and nitrate inhibition of nodule formation in soybean $\mathrm{cv}$ Enrei and its nodulation mutants. J. Exp. Bot. 44, 547-553.

Friend A L, Eide M R and Hinckley T M 1990 Nitrogen stress alters root proliferation in Douglas fir seedlings. Can. J. For. Res. 20, 1524-1529.

Furuya M and Kim B C 2000 Do phytochromes interact with diverse partners? Trends Plant Sci. 5, 87-89.

Gahoonia T S and Nielsen N E 1997 Variation in root hairs of barley cultivars doubled soil phosphorus uptake. Euphytica 98, 177182.

Ge Z Y, Rubio G and Lynch J P 2000 The importance of root gravitropism for inter-root competition and phosphorus acquisition efficiency: results from a geometric simulation model. Plant Soil 218, 159-171.

Genoud T and Métraux J-P 1999 Crosstalk in plant cell signaling: structure and function of the genetic network. Trends Plant Sci. 4, 503-507.

Gilbert G A, Knight J D, Vance C P and Allan D L 2000 Proteoid root development of phosphorous deficient lupin is mimicked by auxin and phosphonate. Ann. Bot. 85, 921-928.

Gilroy S and Jones D L 2000 Through form to function: root hair development and nutrient uptake. Trends Plant Sci. 5, 56-60.

Gresshoff P M, Krotzky A, Mathews A, Day D A, Schuller K A, Olsson J, Delves A C and Carroll B J 1988 Suppression of the symbiotic supernodulation symptoms of soybean. J. Plant Physiol. 132, 417-423.

Grime J P, Crick J C and Rincon J E 1986 The ecological significance of plasticity. In Plasticity in Plants. Ed. D H Jennings and A J Trewavas. pp 5-29. Biologists Limited, Cambridge.

Grusak M A and Pezeshgi S 1996 Shoot-to-root signal transmission regulates root $\mathrm{Fe}(\mathrm{III})$ reductase activity in the $d g l$ mutant of pea. Plant Physiol. 110, 329-334.

Hackett C 1967 A study of the root system of barley. I. Effects of nutrition on two varieties. New Phytol. 67, 287-289.

Hackett C 1972 A method of applying nutrients locally to roots under controlled conditions, and some morphological effects of locally applied nitrate on the branching of wheat roots. Aust. J. Biol. Sci. 25, 1169-1180.

Heard J, Caspi M and Dunn K 1997 Evolutionary diversity of symbiotically induced nodule MADS box genes: characterization of $n m h C 5$, a member of a novel subfamily. Mol. Plant-Microbe Interact. 10, 665-676.

Heidstra R, Geurts R, Franssen H, Spaink H P, van Kammen A and Bisseling T 1994 Root hair deformation activity of nodulation factors and their fate on Vicia sativa. Plant Physiol. 105, 787797.

Heidstra R, Nilsen G, Martinez Abarca F, van Kammen A and Bisseling T 1997 Nod factor-induced expression of leghemoglobin to study the mechanism of $\mathrm{NH}_{4} \mathrm{NO}_{3}$ inhibition on root hair deformation. Mol. Plant-Microbe Interact. 10, 215-220.

Hinson K 1975 Nodulation responses from nitrogen applied to soybean half-root systems. Agron. J. 67, 799-804.

Hobbie L and Estelle M 1995 The axr4 auxin-resistant mutants of Arabidopsis thaliana define a gene important for root gravitropism and lateral root initiation. Plant J. 7, 211-220.

Hodge A, Robinson D, Griffiths B S and Fitter A H 1999 Why plants bother: root proliferation results in increased nitrogen capture from an organic patch when two grasses compete Plant Cell Environ. 22, 811-820.

Hsieh M-H, Lam H-M, Van De Loo F J and Coruzzi G 1998 A PII-like protein in Arabidopsis: putative role in nitrogen sensing. Proc. Natl Acad Sci USA 95, 13965-13970. 
Hunter W J 1993 Ethylene production by root nodules and effect of ethylene on nodulation in Glycine max. Appl. Environ. Microbiol. 59, 1947-1950.

Hutchings M J and de Kroon H 1994 Foraging in plants: the role of morphological plasticity in resource acquisition. Adv. Ecol. Res. $25,159-238$.

Imsande $\mathrm{J}$ and Touraine B $1994 \mathrm{~N}$ demand and the regulation of nitrate uptake. Plant Physiol. 105, 3-7.

Jacobsen E 1984 Modification of symbiotic interaction of pea (Pisum sativum L.) and Rhizobium leguminosarum by induced mutations. Plant Soil 82, 427-438.

Johnson J F, Allan D L and Vance C P 1994 Phosphorus stressinduced proteoid roots show altered metabolism in Lupinus albus. Plant Physiol. 104, 657-665.

Keerthisinghe G, Hocking P J, Ryan P R and Delhaize E 1998 Effect of phosphorus supply on the formation and function of proteoid roots of white lupin (Lupinus albus L.). Plant Cell Environ. 21, 467-478.

Klasson H, Fink G R and Ljungdahl P O 1999 Ssy1p and Ptr3p are plasma membrane components of a yeast system that senses extracellular amino acids. Mol. Cell. Biol. 19, 5405-5416.

Kohls S J and Baker D D 1989 Effects of substrate nitrate concentration on symbiotic nodule formation in actinorhizal plants. Plant Soil 118, 171-179.

Kosslak R M and Bohlool B B 1984 Suppression of nodule development of one side of a split-root system of soybeans caused by prior inoculation of the other side. Plant Physiol. 75, 125-130.

Lainé P, Ourry A and Boucaud J 1995 Shoot control of nitrate uptake rates by roots of Brassica napus L . Effects of localized nitrate supply. Planta 196, 77-83.

Lee K H and La Rue T A 1992 Ethylene as a possible mediator of light-induced and nitrate-induced inhibition of nodulation of Pisum sativum L. cv Sparkle. Plant Physiol. 100, 1334-1338.

Liao H and Yan X L 2000 Adaptive changes and genotypic variation for root architecture of common bean in response to phosphorus deficiency. Acta Bot. Sin. 42, 158-163.

Ligero F, Caba J M, Lluch C and Olivares J 1991 Nitrate inhibition of nodulation can be overcome by the ethylene inhibitor aminoethoxyvinylglycine. Plant Physiol. 97, 1221-1225.

Ligero F, Poveda J L, Gresshoff P M and Caba J M 1999 Nitrate- and inoculation-enhanced ethylene biosynthesis in soybean roots as a possible mediator of nodulation control. J. Plant Physiol. 154, 482-488.

Ling H Q, Pich A, Scholz G and Ganal M W 1996 Genetic analysis of two tomato mutants affected in the regulation of iron metabolism. Mol. Gen. Genet. 252, 87-92.

Lorenz M C and Heitman J 1998 The MEP2 ammonium permease regulates pseudohyphal differentiaition in Saccharomyces cerevisiae. EMBO J. 17, 1236-1247.

Lucas W J 1997 Application of microinjection techniques to plant nutrition. Plant Soil 196, 175-189.

Lynch J and Brown K M 1997 Ethylene and plant responses to nutritional stress. Physiol. Plant. 100, 613-619.

Malik N S A, Calvert H E and Bauer W D 1987 Nitrate-induced regulation of nodule formation in soybean. Plant Physiol. 84, 266-271.

Marschner H 1995 Mineral Nutrition of Higher Plants. Academic Press, London. Melcior W and Steudle E 1993 Water transport in onion (Allium cepa L.) roots: changes of axial and radial hydraulic conductivities during root development. Plant Physiol. 101, 1305-1315.

Merrick M J and Edwards R A 1995 Nitrogen control in bacteria. Microbiol. Rev. 59, 604-622.
Mollier A and Pellerin S 1999 Maize root system growth and development as influenced by phosphorus deficiency. J. Exp. Bot. 50, 487-497.

Moog P R, Vanderkooij T A W, Bruggemann W, Schiefelbein J W and Kuiper P J C 1995 Responses to iron deficiency in Arabidopsis thaliana: the turbo iron reductase does not depend on the formation of root hairs and transfer cells. Planta 195, 505-513.

Nobbe F 1862 Uber die feinere Verästelung der Pflanzenwurzeln. Landwirtschaft. VersStat. 4, 212-224.

Ozcan S, Dover J, Rosenwald A G, Wolfl S and Johnston M 1996 Two glucose transporters in Saccharomyces cerevisiae are glucose sensors that generate a signal for induction of gene expression. Proc. Natl. Acad. Sci. USA 93, 12428-12432.

Peuke A D, Hartung W and Jeschke W D 1994 The uptake and flow of $\mathrm{C}, \mathrm{N}$ and ions between roots and shoots in Ricinus communis L. II. Grown with low or high nitrate supply. J. Exp. Bot. 45, 733-740.

Postma J G, Jacobsen E and Feenstra W J 1988 Three pea mutants with an altered nodulation studied by genetic analysis and grafting. J. Plant Physiol. 132, 424-430.

Pouteau S, Cherel I, Vaucheret H and Caboche M 1989 Nitrate reductase mRNA regulation in Nicotiana plumbaginifolia nitrate reductase-deficient mutants. Plant Cell 1, 1111-1120.

Pozuelo M, Merchán F, Macías M I, Beck CF, Galván A, Fernández E 2000 The negative effect of nitrate on gametogenesis is independent of nitrate assimilation in Chlamydomonas reinhardti Planta 211, 287-292.

Robinson D 1994 The responses of plants to non-uniform supplies of nutrients. New Phytol. 127, 635-674.

Robinson D and Rorison I H 1983 A comparison of the responses of Lolium perenne L., Holcus lanatus L. and Deschampsia flexuosa (L.) Trin. to a localized supply of nitrogen. New Phytol. 94, 263273.

Robinson D and Rorison I H 1987 Root hairs and plant growth at low nitrogen availabilities. New Phytol. 107, 681-693.

Robinson D, Hodge A, Griffiths B S and Fitter A H 1999 Plant root proliferation in nitrogen-rich patches confers competitive advantage. Proc. R. Soc. Londen Ser. B 26, 431-435.

Ruiz-Medrano R, Xoconostle-Cazares B and Lucas W J 1999 Phloem long-distance transport of CmNACP mRNA: implications for supracellular regulation in plants. Development 126, 4405-4419.

Ryan C A 2000 The systemin signaling pathway: differential activation of plant defensive genes. Biochim. Biophys. Acta 1477, $112-121$.

Ryser P, Verduyn B and Lambers H 1997 Phosphorus allocation and utilization in three grass species with contrasting response to $\mathrm{N}$ and P supply. New Phytol. 137, 293-302.

Sattelmacher B and Thoms K 1995 Morphology and physiology of the seminal root system of young maize (Zea mays L.) plants as influenced by a locally restricted nitrate supply. Z. Pflanzen. Bodenk. 158, 493-497.

Schauser L, Roussis A, Stiller J and Stougaard J 1999 A plant regulator controlling development of symbiotic root nodules. Nature 402, 191-195.

Scheible W R, Gonzalez-Fontes A, Lauerer M, Müller-Röber B, Caboche M and Stitt M 1997a Nitrate acts as a signal to induce organic acid metabolism and repress starch metabolism in tobacco. Plant Cell 9, 783-798.

Scheible W R, Lauerer M, Schulze E D, Caboche M and Stitt M 1997b Accumulation of nitrate in the shoot acts as a signal to regulate shoot-root allocation in tobacco. Plant J. 11, 671-691. 
Schiefelbein J, Galway M, Masucci J and Ford S 1993 Pollen tube and root hair tip growth is disrupted in a mutant of Arabidopsis thaliana. Plant Physiol. 103, 979-985.

Schmidt J S, Harper J E, Hoffman T K and Bent A F 1999 Regulation of soybean nodulation independent of ethylene signaling. Plant Physiol. 119, 951-959.

Schmidt W 1999 Mechanisms and regulation of reduction-based iron uptake in plants. New Phytol. 141, 1-26.

Schmidt W, Tittel J and Schikora A 2000 Role of hormones in the induction of iron deficiency responses in Arabidopsis roots. Plant Physiol. 122, 1109-1118.

Scholz G, Becker R, Pich A and Stephan U W 1992 Nicotianamine: a common constituent of strategy I and strategy II of iron acquisition by plants - a review. J. Plant Nutr. 15, 1647-1665.

Schultze M and Kondorosi A 1998 Regulation of symbiotic root nodule development. Ann. Rev. Genet. 32, 33-57.

Shore P and Sharrocks A D 1995 The MADS-box family of transcription factors. Eur. J. Biochem. 229, 1-13.

Skene K R 2000 Cluster roots: their physiology, ecology and developmental biology. Ann. Bot. 85, 899-899.

Snapp S, Koide R and Lynch J 1995 Exploitation of localized phosphorus-patches by common bean roots. Plant Soil 177, 211-218.

Stitt M and Feil R 1999 Lateral root frequency decreases when nitrate accumulates in tobacco transformants with low nitrate reductase activity: consequences for the regulation of biomass partitioning between shoots and root. Plant Soil 215, 143-153.

Thaler P and Pages L 1996 Root apical diameter and root elongation rate of rubber seedlings (Hevea brasiliensis) show parallel responses to photoassimilate availability. Physiol. Plant. 97, 365-371.
Thompson G A and Schulz A 1999 Macromolecular trafficking in the phloem. Trends Plant Sci. 4, 354-360.

Thornton H G 1936 The action of sodium nitrate upon the infection of lucerne root-hairs by nodule bacteria. Proc. R. Soc. London Ser. B 119, 474-491.

Tillard P, Passama L and Gojon A 1998 Are phloem amino acids involved in the shoot to root control of $\mathrm{NO}_{3}{ }^{-}$uptake in Ricinus communis plants? J. Exp. Bot. 49, 1371-1379.

Trull M C, Guiltinan M J, Lynch J P and Deikman J 1997 The responses of wild-type and ABA mutant Arabidopsis thaliana plants to phosphorus starvation. Plant Cell Environ. 20, 85-92.

von Arnim A G 1999 Phytochrome in the limelight. Trends Plant Sci. 4, 465-466.

Watt M and Evans J R 1999 Proteoid roots. Physiology and development. Plant Physiol. 121, 317-323.

Whiting S N, Leake J R, McGrath S P and Baker A J M 2000 Positive responses to $\mathrm{Zn}$ and $\mathrm{Cd}$ by roots of the $\mathrm{Zn}$ and $\mathrm{Cd}$ hyperaccumulator Thlaspi caerulescens. New Phytol. 145, 199-210.

Wiersum L K 1958 Density of root branching as affected by substrate and separate ions. Acta Bot. Neerl. 7, 174-190.

Wilson J K 1917 Physiological studies of Bacillus radicicola or soybean (Soja max Piper) and factors influencing nodule production. Cornell Univ. Agric. Exp. Stn. Bull. 386, 369.

Zhang H and Forde B G 1998 An Arabidopsis MADS box gene that controls nutrient-induced changes in root architecture. Science 279, 407-409.

Zhang H, Jennings A J, Barlow P W and Forde B G 1999 Dual pathways for regulation of root branching by nitrate. Proc. Natl Acad. Sci. USA 96, 6529-6534. 